\title{
Skin closure with polyglycolic acid (Dexon)
}

\author{
A. E. MacKinnon* \\ M.B., B.S., F.R.C.S.
}

S. BROWN

M.B., B.S., F.R.C.S.

The Royal Manchester Children's Hospital, Pendlebury, Manchester M27 1HA

\section{Summary}

Cosmetically satisfactory scars were achieved in 94.5\% of skin crease orchidopexy wounds sutured with subcuticular polyglycolic acid. Of twenty-seven similar wounds closed with interrupted black silk sutures $18.5 \%$ developed hypertrophy at the medial end.

\section{Introduction}

Skin closure with polyglycolic acid (PGA) has been implicated in the production of unsightly scars. Cox and Simpson (1975) found that $50 \%$ of paramedian wounds closed with subcuticular PGA became hypertrophic, compared to $15 \%$ of wounds sutured with silk or nylon. Watts (1975) reported that the results of wound closure with subcuticular PGA were cosmetically unacceptable, and the practice had been abandoned on his unit. Pease (1976) studied the healing of seventy-five wounds closed partly with subcuticular PGA and partly with subcuticular nylon. The wounds were in various directions related to skin creases, and were in patients of a very wide age range. He concluded that there was no significant difference between the results achieved by the two suture materials.

The present authors have studied the results of subcuticular skin closure with PGA in a group of patients undergoing orchidopexy, and have compared them with similar patients whose wounds were closed with interrupted black silk.

\section{Materials and methods}

From January 1974 to December 1975, 173 orchidopexies were carried out on boys aged 18 months to 14 years. Each incision was made parallel to the skin creases. Subcuticular 0000 PGA was used to close 146 wounds, and 27 were sutured with interrupted 000 silk. The wounds were examined between 13 and 37 months after operation.

A scar was considered hypertrophic if it was raised above the surrounding skin and measured more than $1 \mathrm{~mm}$ in width.

\footnotetext{
* Correspondence: Sheffield Children's Hospital, Western Bank, Sheffield.
}

\section{Results}

Of the wounds sutured with PGA, $138(94.5 \%)$ healed with fine linear scars. Of the remaining eight wounds, one had produced an area of hypertrophy at the medial end, which had settled completely by follow-up at 27 months. The remaining seven wounds had hypertrophic segments which were still present at follow-up. One of these wounds had been made through the scar of a previous incision. Persistent hypertrophy was found at follow-up in five $(18.5 \%)$ of the twenty-seven wounds sutured with silk. In both groups the hypertrophy was always at the medial end of the wound, and in no case was it more than $2 \mathrm{~cm}$ in length.

\section{Discussion}

The development of hypertrophy in a scar is more dependent upon the position of the wound, and its relation to skin creases, than to the type of suture material used. Pease (1976) found that none of his skin crease incisions became hypertrophic. Foster (1975) and Jones and Shorey (1976) have also reported satisfactory results with PGA sutures in transverse abdominal wounds. The hypertrophic segments which occurred in the incisions made by the authors were all of short length and all were near the mid-line. The actual distance from the mid-line did not, however, influence the results. It is interesting to note the higher incidence of hypertrophy when black silk was used, although the small size of this group precludes statistical comparison.

The authors have found subcuticular PGA a very useful suture material in paediatric surgery. The unsatisfactory results with PGA reported by Watts (1975) may have been due to inappropriate use of the material in the presence of infection, and where the incision was not parallel to the skin creases. The authors have used PGA in the deep layers as well as for subcuticular skin closure in over 1000 inguinal and other operations during the period of study. However, they do not use it in potentially infected wounds such as appendicitis. They agree with Jones and Shorey (1975) that subcuticular use of this suture material eliminates the trauma of suture removal, as well as producing a satisfactory cosmetic result. 


\section{Acknowledgments}

The authors wish to thank Mr A. Jolleys and Mr S. J. Cohen for allowing them to study their patients.

\section{References}

Cox, A.G. \& Simpson, J.E.P. (1975) Polyglycolic acid suture material in skin closure. Lancet, i, 452.

FosteR, G.E. (1975) Polyglycolic acid sutures and hypertrophic scars. Lancet, i, 1243.
Jones, S.M. \& Shorey, B.A. (1975) Polyglycolic acid suture material in skin closure. Lancet, i, 390.

Jones, S.M. \& Shorey, B.A. (1976) Polyglycolic acid suture and scar hypertrophy. Lancet, i, 775.

Pease, R. (1976) The incidence of hypertrophic scar formation in wounds closed with subcuticular nylon or polyglycolic acid (dexon). British Journal of Plastic Surgery, 29, 284.

Watrs, G.T. (1975) Sutures for skin closure. Lancet, i, 581. 